\title{
Gestão Por Competências - A Relevância Da Auditoria
}

\section{Skills Management - The Relevance Of The Audit}

DOI: $10.46814 / \operatorname{lajdv3n3-031}$

Recebimento dos originais: 01/052021

Aceitação para publicação: 31/06/2021

\section{Adelcio Machado dos Santos}

Doutor em Engenharia e Gestão do Conhecimento (UFSC). Pós-Doutor em Gestão do Conhecimento (UFSC). Docente, pesquisado e orientador do Programa de Pós-graduação em Educação da Universidade Alto Vale do Rio do Peixe (UNIARP). Endereço: Rua Victor Baptista Adami, 800 Centro - Caçador/SC/Brasil. CEP 89500-199.

E-mail: adelciomachado@gmail.com

\section{RESUMO}

Posto que a identificação das competências parta da estratégia organizacional, demanda definição das competências organizacionais e desdobra-se em competências funcionais. A identificação das competências pode ainda se dar no sentido inverso. A análise das competências de cada profissional formaria o portfólio de competências organizacionais e, a partir dessa definição, a organização estabelece a sua estratégia. Conforme essa abordagem, o novo conhecimento sempre inicia pelo indivíduo e é transformado em conhecimento organizacional. No entanto, a consolidação deste modelo gestorial demanda a efetivação de auditoria, para verificação do grau de concretude.

palavras-chave: Gestão por Competências. Competência. Auditoria.

\section{ABSTRACT}

Since the identification of competences starts from the organizational strategy, it demands definition of the organizational competences and unfolds in functional competences. The identification of competences can also occur in the opposite direction. The analysis of the competencies of each professional would form the portfolio of organizational competences and, based on this definition, the organization establishes its strategy. According to this approach, new knowledge always starts with the individual and is transformed into organizational knowledge. However, the consolidation of this management model requires an audit to verify the degree of concreteness.

Key-Words: Management by Competencies. Competence. Audit.

\section{INTRODUÇÃO}

Competências podem ser identificadas como o conjunto de conhecimentos e qualidades profissionais necessárias para que uma pessoa desempenhe com êxito um conjunto de funções e tarefas, pode ser considerada ainda, como um conjunto de conhecimentos e qualidades necessárias para desenvolver com êxito o negócio de uma organização. (LERNER, 2002).

Em tempos de dificuldades financeiras e da pressão sofrida pelas empresas em gerar resultados e satisfazer investidores, além de superar a concorrência acirrada no mercado, as organizações optam 
cada vez mais na aplicação da gestão por competências vinculada à expectativa de rapidez nos resultados. (JANINI, 2003).

No cenário mundial atual, cada vez mais se vislumbra a necessidade de modernização da administração em virtude do acelerado desenvolvimento tecnológico e econômico envolvido nas relações sociais. Colaboradores, com perfil altamente burocrático, enfrentam desafios de adaptação para transformar uma cultura retrógada, que cada vez mais emperra o serviço público e privado. (GONÇALVES, 2010).

Manter a gestão do serviço e estimular a sinergia da equipe de trabalho é um desafio deveras árduo. Uma empresa/organização é uma comunidade de colaboradores/empregados, que demanda ações e reações de produzir, coordenar e transformar conhecimento em capital de valor econômico. Para Janini (2003 p. 12), a empresa é pressionada a apresentar as seguintes capacidades:

\footnotetext{
- Internacionalizar os seus negócios, atuando de forma competitiva em mercados globalizados e em novos grupamentos econômicos regionais;

- Implantar novos arranjos competitivos em resposta às mudanças regulatórias, ao aumento do número de alianças estratégicas e ao aumento do número de aquisições e fusões;

- Utilizar a nova tecnologia de informação disponível; -

- Organizar-se de maneira mais ágil e flexível para atender às pressões por melhoria em desempenho a curto prazo;

- Ofertar produtos e serviços de melhor qualidade;

- Entender melhor as relações entre cliente e fornecedor.
}

A atividade humana não deve ser automática e a competência aflora com o uso das competências influenciadas pelos eventos, comunicação e serviço. (ZARIFIAN, 2001). O evento consiste na atividade que exige do colaborador resolutividades de eventos ou imprevistos que ocorrem no ambiente organizacional, utilizando o conhecimento, a informação e a tecnologia para administrálos. A comunicação nada mais é que o entendimento entre os colaboradores em torno das tarefas dos imprevistos e dos compromissos que garantem as atividades laborais. O serviço é a sobrevivência de uma organização e a fonte de emprego para os colaboradores, além da interação entre empresacolaborador-mercado.

Para Oliveira (2007) competência estratégica significa a capacidade de identificar todas as questões externas ou não controláveis e interligar com as questões internas ou controláveis de uma organização, utilizando os instrumentos administrativos proporcionados pela administração estratégica. Há ainda a competência tecnológica que é a capacidade de obter e deter o conjunto de conhecimentos e de instrumentos administrativos que se aplicam a uma determinada área de atuação.

Para o autor, as competências fazem os envolvidos a mobilizar redes de interação que vivem a mesma situação, fazendo-os assumir responsabilidades de cada envolvido no processo. 
Para Silva (2011), a auditoria é a ferramenta aplicada para verificar a integridade e a conformidade dos sistemas de gestão das organizações públicas e privadas.

No entanto, à medida que consolida este modelo gestorial, faz-se mister realizar periódicas auditorias, para verificação do grau de concretude.

\section{DESENVOLVIMENTO}

Para Leme (2005) as competências são divididas em dois grupos: competências técnicas e competências comportamentais.

As competências técnicas significam tudo o que o colaborador/profissional precisa saber para desempenhar sua função. Representa tudo aquilo que o profissional precisa para ser um especialista tecnicamente. Competências técnicas podem ser procuradas como palavras-chave nos currículos dos candidatos e depois averiguadas em entrevistas e testes práticos.

Já as competências comportamentais, é tudo o que o profissional precisa demonstrar como seu diferencial competitivo e tem impacto em seus resultados, tais como: flexibilidade, criatividade, organização, planejamento, liderança, entre outras.

As características mais destacáveis das competências, de acordo com Lerner (2002), são:

- Independência: que pode ser aplicável em diferentes pontos da estrutura e em diferentes situações de trabalho;

- $\quad$ Especificidade: específica para cada organização;

- Localização: ligada às pessoas. São os empregados os que a aplicam no desempenho diário de suas ocupações;

- $\quad$ Evolução; modificação e evolução das competências dos colaboradores hoje, para adaptá-la às necessidades futuras.

Podem ainda ser incorporadas a essas competências:

- Os conhecimentos: elemento básico para desempenhar com êxito as funções encomendadas;

- $\quad$ As qualidades profissionais: refletem os padrões de conduta e habilidades pessoais necessárias para desempenhar com êxito uma ocupação (conjunto de funções e tarefas que um empregado deve desenvolver).

É preciso esclarecer, porém, de acordo com Lerner (2002), que as organizações modernas mudaram seu estilo de trabalho, tratando as pessoas de maneira bastante dinâmica e flexível, envolvendo-as em múltiplos projetos de negócios ou ocupações, e, portanto podem ser caracterizadas como: 
- $\quad$ Não são elementos estáticos, mas dinâmicos.

- S São um reflexo da atividade que em cada momento se realiza na organização.

- $\quad$ Não têm vocação de perpetuar-se no tempo, como ocorreu historicamente com o conceito de "posto de trabalho".

Esse autor acrescenta ainda, que a definição das ocupações deve basear-se no conceito mais moderno de fluxos de trabalho e processos por projeto, abandonando o esquema mais clássico de divisão de funções estáticas.

Sobre o perfil das competências, Lerner (2002) acrescenta ainda que cada ocupação requer determinado perfil de competências e cada pessoa deve possuir seu perfil de competências, que pode aplicar em diferentes ocupações ou projetos de negócios.

Destarte, muitas organizações modernas fizeram a ruptura acontecer entre o empregado e o tradicional posto de trabalho, já que se pode gerir as ocupações e os empregados independentemente, podendo mantê-los unidos mediante linguagem comum do perfil de competências.

Para Ruano (2007), o entendimento da competência passa pela visão da dimensão estratégica e da dimensão individual. A primeira trata das competências organizacionais e se refere a empresa como um todo. A segunda trata da competência das pessoas que trabalham na organização. Embora conceitualmente se faça uma distinção entre as dimensões, no desempenho da prática organizacional elas estão intimamente associadas.

Para a autora acima citada, a identificação das competências parte da estratégia empresarial, passa pela definição das competências organizacionais e desdobra-se em competências funcionais. A identificação das competências pode ainda se dar no sentido inverso. A análise das competências de cada profissional formaria o portfólio de competências organizacionais e, a partir dessa definição, a organização estabelece a sua estratégia no mercado. Conforme essa abordagem, o novo conhecimento sempre inicia pelo indivíduo e é transformado em conhecimento organizacional.

Por sua vez, a ideia da competência organizacional surgiu a partir da evolução da chamada “visão da empresa baseada em recursos". As competências organizacionais podem ser classificadas de acordo com a sua natureza. De acordo com Fernandes (2006) essas podem ser competências sobre processos, competências técnicas, competências sobre a organização, competências de serviços e competências sociais.

Milles et al. (2002 apud Fernandes, 2006) propõe ainda uma tipologia para competências organizacionais: competências percebidas pelos clientes e competências de apoio, que podem ser técnicas ou sociais. As competências percebidas pelos clientes se apoiam em competências menos visíveis, de natureza técnica ou social, como competência de trabalhar em equipe. 
Uma outra forma de compreensão da competência organizacional é que ela é construída a partir de recursos. São os que articulados e coordenados, podem configurar competências. Uma competência organizacional não seria propriamente competência se apoiasse em um único recurso, como uma máquina, um indivíduo ou mesmo uma pequena equipe. $\mathrm{E}$, ao revés, um único recurso não pode constituir uma competência. Recurso, de acordo com análise de Fernandes (2006), é uma potencialidade, enquanto que a competência é uma ação.

Pensamento comum associa a gestão somente a empresas essencialmente manufatureiras, mormente àquelas que oferecem bens em vez de serviços. Para Martins (2007), essa ideia é equivocada, uma vez que todos os tipos de organizações precisam cumprir seus objetivos e atingir suas metas. Posto que as organizações que não visam a lucros, como as entidades filantrópicas, precisam apresentar resultados positivos para terem condições de garantir, não apenas a sobrevivência da organização, como também a manutenção dos serviços que oferecem, de maneira que consiga manter sua autosustentabilidade.

Esse autor acresce, ainda, que as escolas sejam geridas de maneira estratégica e orientadas por um planejamento que as mantenha focadas em seus objetivos, para que possam concentrar seus esforços na direção de melhores resultados organizacionais, com a finalidade de permitir que obtenham vantagem competitiva sobre seus concorrentes.

Como qualquer outro empreendimento, deve-se submeter a escola à análise de equilíbrio, para que possa identificar e analisar seu posicionamento no mercado onde está inserida, a fim de colocar suas forças a serviço da empresa, desenvolver habilidades para inibir suas fraquezas, reconhecer as oportunidades para poder focar seus objetivos e identificar as possíveis ameaças para desenvolver proteções ou descobrir alternativas a fim de evitá-las.

De acordo com Ribas (2000), a competência pedagógica também é estudada por especialistas, principalmente a competência do professor, do ensino, da escola e da educação. A autora Guiomar Namo de Mello aborda a competência profissional nas dimensões técnica e política, já o autor Pedro Demo, discute a competência formal e política e a construção da competência.

A autora explicita ainda, que autores estrangeiros como Philippe Perrenoud tratam da competência pedagógica aliada a uma nova maneira de abordar as práticas pedagógicas, a formação de professores e a profissão docente. Os trabalhos, na ótica da Sociológica, permitem a apropriação de novos enfoques sobre desigualdades sociais presentes nas práticas pedagógicas. Seus argumentos sobre a formação do professor tem por base uma imagem explícita e realista da profissão; desenvolvimento pessoal e autodomínio; diferenças e mudanças e a complexidade da formação, são de grande importância. 
Reflete-se com isso, a profissão-professor, seu desenvolvimento pessoal, profissional e organizacional, evidenciando o quanto esses elementos estão imbricados e aponta na direção da mudança. Nóvoa (apud Ribas, 2000) entende que a profissão precisa de se dizer e de se contar, sendo essa, uma maneira de compreensão que obriga opções constantes, que cruzam a maneira de ser com a maneira de ensinar, e que desvendam a maneira de ensinar a maneira de ser.

Ao estimular o professor a alcançar o contexto e as condições sociais, políticas e econômicas que influenciam suas concepções e ações, há a reconstrução dialética do seu quer fazer.

Para que os professores consigam agir de maneira eficaz diante de tantos problemas do dia a dia, faz-se necessário estimulá-los a registrar as situações, Perrenoud (1993, p. 109) destaca ainda que:

[...] analisar o que pensaram, sentiram e fizeram. Não para julgá-los, para acentuar a diferença com o 'que teria sido necessário fazer'. Mas sim para ajudá-los a analisar o seu próprio funcionamento, a dominar pouco a pouco os seus impulsos, as emoções excessivas, a hostilidade em face de certas atitudes dos alunos, a indiferença perante alguns sinais. Deste modo, o habitus pode-se construir não em circuito fechado, mas à medida de uma interação entre a experiência a tomada de consciência, a discussão, o envolvimento em novas situações.

Ribas (2000) acrescenta ainda que para pensar reflexivamente é imprescindível um esforço consciente e voluntário que leva à indagação, à ação, à pesquisa, à descoberta uma vez que o pensamento reflexivo faz um ativo, prolongado e cuidadoso exame de toda crença ou espécie hipotética de conhecimento, exame efetuado à luz dos argumentos que a apoiam e das conclusões a que chega.

\section{CONSIDERAÇÕES FINAIS}

A Auditoria se consolida como a ferramenta adequada e completa, capaz de analisar a gestão de competência e uma empresa ou organização.

Cada vez mais o mundo corporativo exige rapidez na prestação dos serviços públicos e privados, exige colaboradores menos burocráticos que utilizem a comunicação na realização de suas tarefas e na resolução dos problemas organizacionais. Também é importante que os colaboradores possuam flexibilidade, criatividade, organização, planejamento, liderança, entre outras.

Ratifica-se nesse trabalho, que na gestão de competência, a auditoria considera a atuação dos colaboradores e auditores envolvidos no processo.

Por fim, emerge a inferência de que a realização periódica de auditoria se faz mister pra verificação do grau de concretude. 


\section{REFERÊNCIAS}

FERNANDES, B. H. R. Competências e desempenho organizacional: o que há além do Balanced Scorecard. São Paulo: Saraiva, 2006.

GONÇALVES, Marli Sorel de Araújo. Gestão por competências: dificuldades e desafios para gestores de recursos humanos do Ministério da Saúde. 2010. Monografia (Especialização em Negociação Coletiva) - Escola de Administração, Universidade Federal do Rio Grande do Sul, Porto Alegre, $2010 . \quad$ Disponível em: https://www.lume.ufrgs.br/bitstream/handle/10183/40352/000817336.pdf?sequence=1. Acesso em: 12 fev. 2021.

JANINI, Renata. Gestão por competências: uma contribuição para obter e manter um desempenho superior. 2003. Dissertação (Mestrado Profissional em Administração de Empresas) - Escola de Administração de Empresas de São Paulo, Fundação Getúlio Vargas, São Paulo, 2003. Disponível em: http://bibliotecadigital.fgv.br/dspace/bitstream/handle/10438/5707/1200303504.pdf?sequence=1\&isA llowed=y. Acesso em: 12 fev. 2021.

LEME, R. Aplicação prática de gestão de pessoas por competências: mapeamento, treinamento, seleção, avaliação e mensuração de resultados de treinamento. Rio de Janeiro: Qualitymark, 2005.

LERNER, W. Competência é essencial na administração. São Paulo: Global, 2002. (Coleção Contato Imediato)

MARTINS, M. A. P. Gestão educacional: planejamento estratégico e marketing. Rio de Janeiro: Brasport, 2007.

OLIVEIRA, D. de P. R. de. Administração estratégica na prática: a competitividade para administrar o futuro das empresas. São Paulo: Atlas, 2007.

PERRENOUD, P. Práticas pedagógicas, profissão docente e formação. Lisboa: Publicações Dom Quixote, 1993.

RIBAS, M. H. Construindo a competência: processo de formação de professores São Paulo: Olho d'água, 2000.

RUANO, A. M. Gestão por competências: uma perspectiva para a consolidação da gestão estratégica de recursos humanos. Rio de Janeiro: Qualitymark, 2005.

SILVA, Alexandre Nixon Raulino Soratto da Silva. Auditorias de sistema de gestão: competências para agregação de valor. 2011. Tese (Doutorado em Engenharia e Gestão do Conhecimento) Programa de Pós-Graduação em Engenharia e Gestão do Conhecimento, Universidade Federal de Santa Catarina, Florianópolis, 2011. Disponível em: https://repositorio.ufsc.br/xmlui/bitstream/handle/123456789/95832/295110.pdf?sequence=1\&isAllo wed=y. Acesso em 12 fev. 2021.

ZARIFIAN, P. Objetivo competência: por uma nova lógica. São Paulo: Atlas, 2001. 